\title{
Guiding Role of Professional Concept in Higher Educational Reform
}

\author{
Shaofang Shi \\ Library of Minnan University of Science and Technology, Shishi, 362700, CHINA \\ Shuyan Xu \\ Dean's Office of Minnan University of Science and Technology, Shishi, 362700, CHINA
}

Received 9 July 2017 - Revised 17 August 2017 - Accepted 20 September 2017

\begin{abstract}
As a basic quality requirement for students entering into the workplace and the key to construction of characteristic high schools, professional concepts can help universities reshape the concept of talent cultivation. Starting from the connotation of professional concept as well as optimizing and innovating the curriculum system setting, we should pay attention to students' subjective initiative in the process of cultivation for professional concept. Focusing on the change of students' professional position in future and the concept of lifelong education, the reform of higher education should actively explore the professional concept. Based on employment standard in social enterprises and evaluation feedback, we should comprehensively use service of personalized education to drive and strengthen the students' professional concept. We should also carry out education of traditional Chinese moral, spiritual of the times and citizens' moral to effectively solve the problems that whom the university students should serve for and how to serve; university students should be cultivated to combine "occupation dream" with university education to correctly handle the relationship between personal career dream and profession. Through systematic vocational education, students can choose contents of professional education according to their own interests, abilities and needs of enterprises and establish their own professional development planning to love what they do and try their best to be expert in their fields so that they can comprehensively strengthen occupation identity. Combining with the professional concept, curriculum system in higher education can deepen the comprehension of university students to what they have learned, make what they have learned stereoscopical, stimulate the students' occupation enthusiasm, encourage students to follow the path of professional awareness, career identity, and professional personality as well as realize the change from university students to career man. In order to establish occupation identity, university students should actively establish their plan for career, understand the relevant information on work outside the enterprise and establish their own career aims to reduce confusion and bewilderment after graduation and at last, they can grasp the opportunity in the workplace to get occupation power beyond the other people.
\end{abstract}

Keywords: professional concept, curriculum system, higher education, lifelong education

(C) Authors. Terms and conditions of Creative Commons Attribution 4.0 International (CC BY 4.0) apply. Correspondence: Shuyan Xu, Dean's Office of Minnan University of Science and Technology, Shishi, 362700, China, +86 18505957777 . 


\section{Contribution of this paper to the literature}

- New enrollments should be carefully guided, allowing students to understand their own personal characteristics-including their own personality and ability to work, to clearly comprehend their own interests and values, to make career planning clear and to strengthen professional development goals.

- Students are guided carefully when graduating from university. It is required that students should have a clear self-realization and analysis before graduation and understanding of the objective and subject factors.

- The construction of ideological politics must be strengthened. In the new period of the cultivation for students' professional quality, in addition to expanding the educational space and resources outside the classroom, the basic role of traditional ideological politics cannot be ignored. It is necessary to excavate, integrate, explore and update the teaching ideology and method in ideological politics to realize advance with the times and common development and meet the demand of society for "career man".

\section{INTRODUCTION}

The rapid economic change promotes university students facing a tough job market at any time. Because of subjecting to traditional working concepts, students are more likely to push themselves to the stable income and decent work (Duan, Wang, and Jia, 2015). Therefore, state-owned enterprises and public institutions become their initial choice. It is difficult for students to meet the employment standards of enterprises due to the passive professional concept (Li,2015). The criterion of employment and selection in modern enterprises has changed in original grades, professional knowledge, education and other aspects, thus, individual comprehensive qualities such as view of employment, dream, dedication, responsibility, loyalty, innovation consciousness and team cooperation etc. have become the key factors. Based on superior professional talent cultivation and emphasizing knowledge and skill, the reform of higher education will put professional concept in the first place of education. In virtue of professional concept, it will realize talents change from "quantity" to "quality" to meet the job requirements and assessment standards of modern enterprises. Starting from the change of students' major responding to the demands of future occupation, we should gradually cultivate the concept of lifelong education; taking employment criterion of enterprises as guidance for cultivating professional concept to build co-operational platform between universities and enterprises and enhance students' comprehensive occupation quality. At the same time, we should closely centre on the feedback system of professional concept to provide students with individualized vocational guidance service (Mi, Yuan, and Jia, 2015).

\section{REVIEW OF RESEARCH STATUS}

By strengthening the close connection with social reality, grasping the changing characteristics of future career is the foundation of constructing reasonable expectation for career planning. Students are in the stage of changing for concept and the ideal occupation as well as environmental change will transform students' thoughts and ideal occupation. These objective factors should be considered in planning for occupation to further create characteristic professional development plan for each student and make career plan for future development (Liu, 2017).

The interaction with the environment allows people to accumulate knowledge and experience and the practice of integrating with the real environment are more likely to stimulate students' desire for knowledge, and to speed up the understanding and internalization of knowledge. The application of professional concept in higher education must have some basic characteristics to deepen the students' understanding of the connotation of professional concept and transform it into their own professional quality. Firstly, the authenticity of occupation practice must be paid attention to: real work environment can help students understand their professional life and the connection between their major and work to gradually transform, optimize and deepen the knowledge system (Roux, Kingsford, and Mccool, 2015). Secondly, the diversity of knowledge and skill needed by modern occupation and elaboration of social division put people in extremely complex network, thus, we need to establish educational dialogue, communication and cooperation. Among them, students can fully understand themselves and know others: knowing themselves is a comprehensive and multi-angled understanding, including their own personality, 
hobbies, outlook on life and values and so on to understand and master work expectations and abilities of others; students should recognize the strengths of others to compensate for their weaknesses to further show the value of their occupation to the society and to be used by society and enterprises (Sun, 2016). Thirdly, the challenge goals predetermined by professional education and limit factors must be clear to mobilize students' learning initiative and promote students' rational development. Professional teachers should actively make use of various teaching methods to introduce students into the situation of professional practice and ensure that teachers are in the real working atmosphere so as to fully study, sample and comprehend (Liu, 2016).

\section{METHODS}

After graduation, university students should base themselves on the society, adapt themselves to the society and realize themselves, which is the common demand for individuals and society. During four years' learning and life, higher education must insist on starting from the view of occupation and letting students take the demands of future occupation as guidance to gradually create a correct view of professional concept and to cultivate students' abilities of cognition, work, living and viability. It also has professional dream, occupation moral, work groups and occupation career in mind (Cai, 2015). At first, for the decision-making ability, higher education should see the nature of things, set up long-term and short-term goals, constantly come up with new ideas at working, be good at innovation and dare to put forward new ideas. When facing problems, it can quickly see the essence of things and seize the key to problems quickly and accurately; Secondly, for the ability of adaption, when facing rapid changes in economy and technology, students must fast renew their own occupation skills and grasp knowledge and technology in the specific professional fields to cultivate their own compound skills, ability of selfstudy and innovative spirit as well as quickly adapt to the future social change; Thirdly, during the process of team development, students need to be good at communication and cooperation with others, play a leading role in the team and effectively promote the completion of work with persuasion when talking. Excellent career man in the team must be able to express their own views, have a good adaptability and ability to listen and have clear thinking and coordination (Ying, 2015); finally, for the aspect of professional teachers, teachers are the key to the implementation of education. In the application of professional concept to higher education, teachers should be eager to innovate education, effectively enhance the ability of self education, adhere to lifelong learning and improve knowledge of self professional education to create a unique teaching style (Huo, 2015).

\section{Construction of Cointegration Model}

It is assumed that in the process of higher education reform, the mean, variance and covariance related to the random variable $V_{t}$ are fixed and for any sample $t, m, n$ :

$$
\left\{\begin{array}{l}
E\left(V_{t}\right)=E\left(V_{t+m}\right) \\
\operatorname{Var}\left(V_{t}\right)=\operatorname{Var}\left(V_{t+m}\right) \\
\operatorname{Cov}\left(V_{t}\right)=\operatorname{Cov}\left(V_{t+m+n}\right)
\end{array}\right.
$$

It is believed that the process of higher education reform is stable and for all values , $m, n$, the sequence of educational reform is steady, thus, it can be recorded as $V_{t}: I(0)$. Under the guidance of the professional concept, the unstable sequence of educational reform does not have this characteristic and the current value of the sequence will also be affected by a numerical change a long time ago. The unstable data sequence of educational reform is integration, which can be noted as $V_{t}: I(1)$. When it is fully differentiated, it can be stable. Similarly, the stability of data for whole educational reform also needs to be tested and when the unstable data is differentiated, it will be made stationary (Muller, 2015).

After the multiple stationary sequences are processed by linear regression, we cannot get the expected stationary sequence, but under the condition that goodness of fit in the new sequence $R^{2}$ is higher and statistics $D W$ is relatively low, the stability of sequence variable is firstly determined when constructing the cointegration model of higher education reform (Snoen, and Waale, 2015). After determining the data stationarity of variable, it is assumed that there are variables of time sequence $Y_{t}$ and $X_{t}$ among professional concept of higher education. If they are stable, the relative regression model is: 


$$
y_{t}=a+\alpha x_{t}+u_{t}
$$

When regressively analyse the relative relationship between them, the unstable time sequence of professional concept and higher education reform needed to be turned into stable time sequence. It is a hypothesis that the variables $X_{1 t}, X_{2 t}, H, X_{i t}(i \geq 2)$ in the process of educational reform are a set of sequences $I(k)$, and there are relative real numbers $\beta_{1}, \beta_{2}, H, \beta_{i}$, which are not all zero. If it meets the relationship of linear combination $\beta X$ is $I(k-p)(p>0)$, the sequence $(k, p)$ can be called cointegration. $\beta$ can be called relative cointegrated vector, among which $X=\left(X_{1 t}, X_{2 t}, \ldots, X_{i t}\right)$, and $\beta=\left(\beta_{1}, \beta_{2}, \ldots, \beta_{i}\right)$. A sequence cointegration can be used to explain that the stable relationship lies between variables of the higher educational reform for a long time and if the sequence $(k, p)$ is cointegrated, variables are not far apart from each other. They are not affected by some changes within a long time, even if they are affected, they will return to stable mean in the short term.

\section{RESULTS}

Before analyzing the effect of higher educational reform guided by professional concept, the method of Pearson correlation coefficient is used to determine the relevance between them. The absolute value of Pearson correlation is closer to 1 , and the correlation between them is stronger. The statistical analysis software-Eviews7.2 is utilized to calculate the correlation coefficients, and the results are shown in Table 1:

Table 1. Correlation Coefficients between Logistics and the Development of Commercial Circulation

\begin{tabular}{ccc} 
& LNCEVA & LNLEVA \\
\hline LNCEVA & 1 & 0.9156 \\
\hline LNLEVA & 0.9378 & 1 \\
\hline
\end{tabular}

From Table 1, it is shown that the Pearson correlation coefficient between professional concept and higher educational reform $>0.8$, which indicates a higher correlation and a stronger dependence between them. It can be further analysed by virtue of cointegration regression.

The cointegration test is adapted in the sequences CEVA and LEVA and the results are shown in Table 2:

Table 2. Cointegration Test of LNCEVA and LNLEEVA

\begin{tabular}{ccccc}
\hline Variable & Coefficient & Std.Error & t-StatisticProb. & Std.Errort \\
\hline $\mathrm{C}$ & 0.0914 & 0.0183 & 2.5501 & 0.0129 \\
\hline $\mathrm{LEVA}$ & 0.6147 & 0.1028 & 5.5721 & 0.0203 \\
\hline $\mathrm{LLI}$ & 0.5143 & 0.1127 & 2.8791 & 0.0000 \\
\hline $\mathrm{NLPE}$ & 0.4291 & 0.0581 & 1.9611 & 0.0701 \\
\hline $\mathrm{R}^{2}$ & 0.4960 & F-statistic & 6.9845 & $/$ \\
\hline Durbin-Watsonsta & 1.78 & $/$ & $/$ & $/$ \\
\hline
\end{tabular}
as follows:

According to the results of cointegration test for LNCEVA and LNLEEVA, regression model can be shown

$$
\begin{aligned}
& \operatorname{lnCEVA}=0.0914+0.6147 \ln L E V A \\
& +0.5143 \ln L L I+0.4291 \ln N L P E \\
& \quad 0.1211 E_{T-1} \\
& t=2.55 \quad(5.57) \quad(2.87) \quad(1.96) \\
& R^{2}=0.4960 \quad F=6.9845 \quad D W=1.78
\end{aligned}
$$

According to the results of cointegration regression test, $1 \%$ increase in each educational concept will cause $0.6147 \%$ increase in results of educational reform. Because of remarkable short-term adjustment coefficient, it is assumed that the fluctuation of students' career concept in short period is not consistent with the long-term equilibrium state, which will pull it back to the corresponding equilibrium state with $12.11 \%$ of adjustment tension. The match value of the above-mentioned values is shown in Figure 1, where the fitting effect is relatively good. 


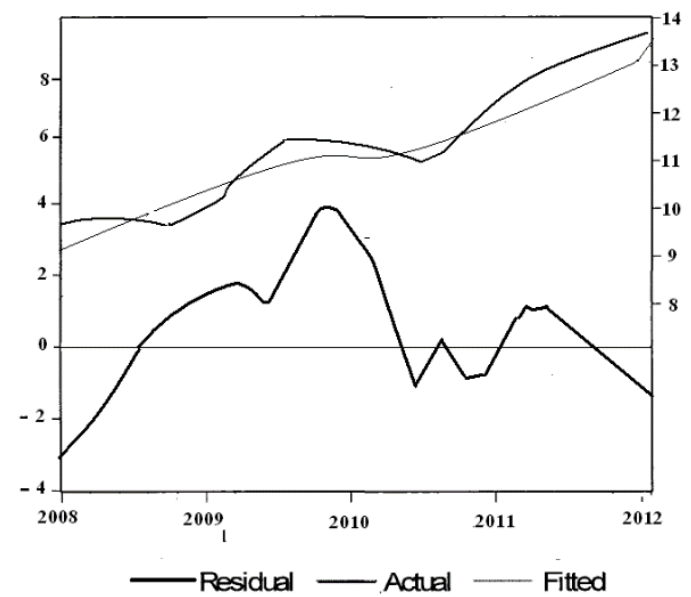

Figure 1. Match Figure of Professional Concept and Educational Reform

The professional concept is a concept and realm of career man, reflecting the rational cognition, pursuit of dream and maintenance of human's educational idea. The professional concept is an important force for university education and higher education should have special features, entelechy and vitality. It also should start local, face the world and study market to accurately grasp the guiding role of professional concept. A variety of ways of running schools should adapt to professional concept to adjust strategic reform direction of talent training and establish diverse and comprehensive higher education.

\section{DISCUSSION}

Higher education has a certain limits in cultivation of professional concept. When students enter into the hustle and bustle of social competition from the quiet campus, university students have to face a huge psychological gap and the concept of lifelong education can make up the gap, which is in line with the future direction of educational development. Universities should actively cooperate with the national macro strategy, combining with adult education, pre-career education, continuing education, social communities and enterprise to construct multilevel professional education system, realize connection and communication for students admission to society from the campus, meet the increasing learning needs and gradually adapt to the rapid development and reform of social economy.

At present, the system of professional lifelong education in China has narrow professional training and less training objects, which will seriously affect the rapid development and popularization of the concept of professional lifelong education. Lifelong education system should adhere to the principle of diversity and universality, from the perspective of openness, science and pertinence to strengthen the prediction about the demand for talents. To adapt to professional change under structure changes of social economy, the system should gradually optimize the teaching policy and professional settings and timely increase new teaching content. It should be beneficial to the sustainable development of students' career, deepen reform concept and adapt to the requirements of lifelong education.

\section{CONCLUSION}

The development of enterprises must improve professional level, professional morals and human cultivation of career men. As the "source" of enterprise's talents, during the educational reform, through deepening professional concept and constant self improvement and development, universities follow the strategic goals of talent training to strive to cultivate students' professional quality and help students to set up accurate sense of occupation and values, ensuring the match of university students with enterprise standards and laying a 
foundation for entering the society, and at the same time, helping students to understand the lifelong development planning as well as gradually growing into a talent of country and society.

\section{REFERENCES}

Cai, Q. S. (2015). Reflection on the Connection between Secondary and Higher Vocational Education Promoted by Modern Apprenticeship. Journal of Southern Vocational Education, 15, 89-90.

Duan, Z. P., Wang, S., \& Jia, S. S. (2015). On talent training target of Higher Vocational Education under modern vocational education system. Chinese Vocational and Technical Education, 15, 66-68.

Huo, X. (2015). On the Role of the Demonstrative Higher Vocational Universities in the Construction of Modern Vocational Education System. Vocational \& Technical Education, 45, 99-101.

Li, C. Q. (2015). Meta analysis of University Teachers' Job Burnout. Chinese Journal of School Health, 36, 67-69.

Liu, C. (2016). The Guiding Role of Teachers in English Teaching in Higher Vocational Universities. Journal of Chongqing College of Electronic Engineering, 35, 45-50.

Liu, Q. (2017). The Realistic Predicament and Rational Thinking of the "Spirit of the Craftsman" in Higher Vocational Education. Higher Vocational Education Exploration, 25, 96-100.

Mi, Z. W., Yuan, W., \& Jia, A. D. (2015). The Comparison and Revelation of the Vocational Ability Standards of University Counselors in China and America. Heilongjiang Researches on Higher Education, 23, 47-50.

Muller, J. (2015). The future of knowledge and skills in science and technology higher education. Higher Education, 70, 409-416.

Roux, D. J., Kingsford, R. T., Mccool, S. F., McGeoch, M. A., \& Foxcroft, L. C. (2015). The Role and Value of Conservation Agency Research. Environmental Management, 55, 1232-1245.

Snoen, E., \& Waale, M. B. (2015). Education for Vocational Teachers - Digital Storytelling as a Tool for Reflection. Journal of Neurogenetics, 23, 147-155.

Sun, Z. (2016). Socialist Core Values Guiding Higher Vocational Students' Ideological and Political Education. Journal of Beijing Polytechnic College, 23, 77-79.

Ying, W. U. (2015). Inspiration From English-speaking Skills Contest for English Teaching Reform in Higher Vocational Universities. Overseas English, 27, 69-70.

\section{http://www.ejmste.com}

